\title{
A justiça de proximidade, aproximar a justiça dos cidadãos?*
}

\author{
Proximity justice, an approximation of \\ justice and citizens?
}

Anne Wyvekens**

\begin{abstract}
Resumo: A noção de justiça de proximidade possibilitou o aparecimento, nos anos 90, das Maisons de la justice et $d u$ droit - MJD [Casas de justiça e direito] que pretendiam reafirmar a presença do direito nos bairros, melhorar a escuta dos seus habitantes, facilitar seu acesso à justiça, restabelecer um laço entre os autores de delitos e suas vítimas, permitindo também um tratamento judiciário mais rápido da pequena delinquência. Essas MJD nascidas de iniciativas locais e de práticas muito variadas foram substituídas, a partir de 2002, pelas "jurisdições de proximidade" integradas ao edifício judiciário, cujas competências foram em seguida fortemente ampliadas. Esta institucionalização traduziu-se em abandono da preocupação qualitativa em proveito de uma gestão quantitativa dos contenciosos de massa. E mesmo quando o recrutamento dos juízes de proximidade deveria abrir-se o mais possível à sociedade civil, sua diversificação foi singularmente restringida após uma decisão do Conselho Constitucional.
\end{abstract}

Palavras-chave: Justiça de proximidade; acesso à justiça; contenciosos de massa

Abstract: In the1990's, the idea of Proximity Justice gave birth to the Maisons de la justice et du droit - MJD [Houses of Justice and Law] that aimed to reaffirm the presence of the law in neighborhoods, to improve the attention given to its inhabitants, to facilitate their access to justice, reestablish links between the perpetrators of criminal offences and their victims, allowing a faster judicial treatment of small delinquency. These MJD, founded by local initiatives and several other practices, since 2002, were replaced by the "jurisdictions of proximity" integrated to the judicial building, whose competencies were then greatly expanded. This institutionalization resulted in the abandonment of qualitative preoccupation in favor of a quantitative management of mass disputes. And even if the judges of proximity recruitment should open up to civil society, its diversification was singularly restricted after a decision of the Constitutional Council.

Keywords: Proximity Justice; access to justice; mass disputes.

\footnotetext{
* Tradução do francês de Jacqueline Sinhoretto.

**Pesquisadora do Centre d'Études et de Recherches de Science Administrative, Université Paris 2, Paris, França. <anne.wyvekens@cersa.cnrs.fr>.
}

\begin{tabular}{|c|c|c|c|c|c|}
\hline Civitas & Porto Alegre & v. 10 & n. 2 & p. 233-244 & maio-ago. 2010 \\
\hline
\end{tabular}


A justiça de proximidade ${ }^{1}$ : inovação ou trompe-l'oeil'? Justiça melhorada ou justiça barateada? A instituição é recente: as jurisdições de proximidade foram criadas por uma lei de setembro de 2002 e os primeiros juízes de proximidade assumiram as suas funções no outono de 2003. A noção porém tem história mais longa. Falava-se anteriormente de "justiça de proximidade" para designar a justiça dita "de gabinete" dos juízes da infância. Esta proximidade do juiz, desembaraçado de sua toga e do tablado, recebendo o jovem em seu escritório, é a que se qualifica hoje de humana, sendo a aproximação entre o juiz e os jurisdicionados sempre associada, num momento ou noutro, à figura do saudoso juiz de paz. A história contemporânea da justiça de proximidade como "conceito" começa no início dos anos 1990, integrando uma política urbana $^{3}$, nos bairros ditos "fora-da-lei". Entre as Maisons de justice et du droit - MJD [Casas de justiça e do direito] do Val d'Oise e as centenas de juízes de proximidade hoje em posto, um "conceito" nasceu, evoluiu, depois foi "mutado", para tomar forma institucional. É à luz deste percurso que gostaríamos de evocar a justiça francesa de proximidade como a história de um duplo impulso, mas também de uma dupla incompletude.

\section{Duas justiças de proximidade}

A expressão "justiça de proximidade" abrange em sua aparente evidência, além de um número não negligenciável de questões de fundo comuns, dois movimentos, dois conjuntos de práticas profundamente dessemelhantes. $\mathrm{O}$ primeiro vem do campo e refere-se sobretudo à problemática da delinquência e da insegurança, o segundo procede de uma reforma legislativa e põe o acento no tratamento dos pequenos litígios entre os particulares.

\section{"De baixo para cima": casas de justiça nos bairros "fora-da-lei"}

Justiça distante, justiça inadaptada - o diagnóstico e as primeiras respostas têm lugar nas periferias. Nos bairros ditos de exclusão, nos quais a

1 A expressão "justiça de proximidade" às vezes é utilizada em um sentido amplo, incluindo do acesso ao direito à informação jurídica. Aqui estão em questão somente os aspectos judiciais da noção.

2 Trompe-l'oeil é uma expressão criada na pintura para designar uma imagem que engana o olho, criando diversas percepções em perspectiva (Nota da tradutora).

3 Politique de la ville no original, é uma política transversal, global, territorializada e interministerial. Sua missão consiste em mobilizar, organizar e estruturar as intervenções públicas sobre os territórios definidos como prioritários em razão das dificuldades em que se encontram seus habitantes (ambiente degradado, desemprego, fracasso escolar, delinquência, guetificação...), através de parcerias. As ações são empreendidas em múltiplos domínios: ação social, moradia, urbanismo, emprego, desenvolvimento econômico, segurança e prevenção da delinquência, educação, igualdade de oportunidades. 
política urbana prodigaliza sua transversalidade e a sua parceria, delinquência e sentimento de insegurança reclamam da instituição judiciária respostas mais adaptadas que a da tradicional persecução no tribunal penal, demasiado pesada em muitos casos, tardia ou mesmo ausente em outros. Os magistrados têm dificuldade em ocupar o seu lugar nos conselhos comunais de prevenção da delinqüência, criados na segunda metade dos anos 1980 em conformidade com recomendações do Relatório Bonnemaison ${ }^{4}$ : nem a parceria e a confrontação que esta supõe com os governantes eleitos, nem a perspectiva de "fazer o social" mais do que "dizer o direito" ou reprimir os entusiasmam, com raras exceções. Poucos membros do ministério público estão na origem do que se chamará logo "justiça de proximidade": ponto de encontro entre a política urbana (abordagem local, proximidade) e a política penal (justiça), inscreverse-á no quadro mais amplo "de uma política judiciária urbana” que conhecerá seus dias de glória.

A primeira Maison de justice et du droit foi criada em 1990 num bairro "sensível"5 de Cergy-Pontoise, e foi rapidamente seguida por três outras, com as mesmas características. Proximidade geográfica: trata-se de fazer ver a justiça em lugares em que o direito parece ter desertado. A justiça de proximidade é primeiro uma implantação imobiliária. Certamente, estas casas não são vazias. Os membros do ministério público que lá oficiam praticam diversas formas de suspensão condicional do processo [classement sous condition], inspirados na mediação penal ou comunitária que tinha começado a experimentar, nomeadamente, o procurador Georges Apap em Valence (Apap, 1990). A pequena infração é convertida num conflito, que será regulado por um terceiro neutro disposto mais a aproximar as partes do que a aplicar uma sanção. Proximidade humana: primeiro a escuta, uma preocupação de compreender, de restabelecer uma relação não somente entre a justiça e os cidadãos, mas igualmente entre o autor de um delito e sua vítima. Vêm em seguida as casas de justiça e direito de Lion, onde a "mediação" se articula com um dispositivo relativo ao conjunto do contencioso penal, o "tratamento em tempo real". Trata-se de acelerar o processo de tratamento das infrações instaurando entre o

\footnotetext{
4 O relatório Bonnemaison foi realizado em 1982 por uma comissão composta de prefeitos de cidades médias e importantes sobre o tema das respostas à insegurança urbana. O relatório se intitula "Face à la délinquance: prévention, répression, solidarité", e consituiu o ponto de partida de uma reforma da prevenção da delinquência: abordagem transversal, mobilisando parceiros locais animados pelo governo municipal. Esta nova política de prevenção é um dos elementos da "política urbana".

5 Quartiers sensibles é uma expressão comumente utilizada em francês para referir-se aos bairros com grandes problemas sociais, como a dificuldade de integração dos jovens, o desemprego, a violência e os conflitos raciais (Nota da tradutora).
} 
ministério público e os oficiais de polícia judiciária, cada vez que uma infração é elucidada, um modo de orientação dos procedimentos por via telefônica que substitui o tradicional, e às vezes bem lento, "correio penal" ${ }^{\text {. Proximidade }}$ temporal: responder ao crescimento da pequena delinqüência não é somente responder diferentemente, é também reagir mais rapidamente, lutar contra o sentimento de impunidade dos autores, o sentimento de abandono das vítimas, tentar pôr em movimento uma máquina judiciária suficientemente estrangulada.

Este primeiro período da justiça de proximidade caracteriza-se para além da sua dimensão essencialmente penal - pelo seu pragmatismo, gerando uma grande diversidade de práticas que, por muito tempo, nenhuma pressão vinda de cima virá canalizar. Cada procurador inventa - ou não -, em colaboração com os governantes locais ${ }^{7}$, a "sua" justiça de proximidade. Antes de serem consagradas pela lei, em $1998^{8}$, as casas de justiça foram objeto apenas de um anexo de circular em $1992^{9}$, depois em 1996 de uma circular ${ }^{10}$ que se limitou a descrever os três "pilares": à mediação penal, com efeito, rapidamente vieram acrescentar-se o acesso ao direito (auxílio às vítimas $\mathrm{e}$ outras consultas jurídicas diversas) e a parceria local.

Ao longo dos anos, as MJD multiplicam-se ${ }^{11}$ e sua atividade penal tende a diminuir para deixar um lugar mais central à atividade de acesso ao direito. De judicial, centrada na resposta à delinquência, a justiça de proximidade, sempre implantada nos bairros em dificuldade, evolui para uma abordagem mais "civil", jurídica e de serviço, análoga à dos postos de serviços públicos que começam a se instalar nos mesmos bairros. Tal é o sentido da impulsão dada às casas de justiça da segunda geração, no fim dos anos 1990, pela secretaria geral de coordenação da política judiciária urbana que tinha sido criada junto à direção de assuntos criminais da Chancelaria alguns anos antes e que desaparecerá em 2001. Paralelamente - e isto explica em parte -, a "mediação penal", cada vez mais atrelada ao tratamento em tempo real e consagrada pela lei ${ }^{12}$, tornou-se "terceira via", derivando em diversas "alternativas ao processo", no interior dos próprios tribunais...

\footnotetext{
${ }^{6}$ Para uma definição mais completa e atualizada do tratamento em tempo real, ver Bastard, Mouhanna (2006).

7 A criação de uma casa de justiça procede de uma iniciativa comum justiça/municipalidade.

${ }^{8}$ Lei no ${ }^{\circ} 98-1163$ de 18 de dDezembro de 1998 relativa ao acesso ao direito e à resolução amigável dos conflitos.

${ }^{9}$ Circular NOR.JUS.D.92-30022 C do 2 de outubro de 1992.

${ }^{10}$ Circular NOR.JUS.D.96-30031 C do 19 de mMarço de 1996.

${ }^{11}$ Os números disponíveis no sítio internet do Ministério da Justiça francês referem-se, em 31 de janeiro de 2005, a 117 Maisons de justice et du Droit, repartidas em 55 departamentos.

12 Lei n ${ }^{\circ} 99-515$ de 23 de junho de 1999 que reforça a eficácia do procedimento penal.
} 


\section{"De cima para baixo": uma jurisdição de proximidade em cada tribunal de recurso}

Em 2002, é uma nova justiça de proximidade que nasce. De bricolagem judicial, às vezes sistematizada, mas permanecendo essencialmente uma coisa de militantes, a justiça de proximidade passou à promessa eleitoral $\mathrm{e}$ em seguida, muito rapidamente, à institucionalização. Se ela figura tanto no programa de Lionel Jospin quanto no de Jacques Chirac, como resposta a preocupações que se assemelham - pelo menos de longe - às que tinham servido de base à criação das casas de justiça, é no entanto algo de muito diferente que vai ser instaurado logo após as eleições da primavera de 2002. A justiça de proximidade é imediatamente criada pela lei e toma a forma de um órgão jurisdicional novo, que vem integrar-se ao edifício judiciário.

A lei de nove de setembro de 2002 prevê a criação, na competência de cada tribunal de recurso, de novos órgãos de primeira instância, "as jurisdições de proximidade", compostas por juízes não profissionais, cuja instauração tem por objetivo, de acordo com a exposição de motivos da lei orgânica de 26 de fevereiro de 2003, "trazer aos pequenos litígios da vida cotidiana, bem como às pequenas infrações às regras de conduta elementar da vida em sociedade, para os quais não existe atualmente solução apropriada, uma resposta judicial simples, rápida e eficaz".

Originalmente, a jurisdição de proximidade era competente, em matéria civil, para as ações pessoais materiais movidas por pessoas físicas, para as necessidades de sua vida privada, não excedendo 1.500 euros ou de valor indeterminado se tivessem por origem a execução de uma obrigação cujo montante não excedesse esta soma, assim como para as ordens de pagamento relativas a este contencioso. Em matéria penal, aplicava-se à maior parte das contravenções das quatro primeiras classes cometidas pelos maiores e pelos menores e algumas contravenções de quinta classe cometidas por maiores. O juiz de proximidade podia ainda ser delegado pelo presidente do tribunal para a validação de medidas de composição penal (alternativas ao processo) decididas pelo ministério público.

Com a lei de 26 de janeiro de 2005, a competência civil de juízes de proximidade foi consideravelmente estendida: eles recebem atualmente contenciosos civis de até 4.000 euros, movidos por pessoas físicas para as necessidades de sua vida privada, mas também profissional, ou pelas pessoas jurídicas, bem como, nas mesmas condições anteriores, dos litígios de um valor indeterminado que têm por origem a execução de uma obrigação cujo montante não exceda 4.000 euros. Quanto à competência em matéria penal, o 
seu domínio foi clarificado: são doravante competentes para as quatro primeiras classes de contravenção, sendo o tribunal de polícia competente para a quinta. A lei nova prevê, além disso, que os juízes de proximidade possam agora ter assento nas formações colegiais dos tribunais correcionais.

O projeto não deixa de evocar, mutatis mutandis, as diferentes dimensões da "proximidade" que figuravam no centro da "primeira" justiça de proximidade. A proximidade humana, com a preocupação de "oferecer um tratamento judicial renovado aos litígios da vida cotidiana, incrementando a conciliação e, assim, por isso, a escuta dos jurisdicionados"13, é também uma proximidade dita processual: "obedecendo a regras processuais simples e propiciando a conciliação e a escuta das partes, [a jurisdição de proximidade] deve concorrer para dissolver a imagem por vezes disseminada entre os jurisdicionados de uma justiça opaca e complexa". A proximidade geográfica não está ausente, embora seja menos destacada que no caso das maisons de justice: a jurisdição de proximidade está atrelada à competência territorial do tribunal de instância e é sabido que o mapa judicial, o qual corresponde cada vez menos às evoluções demográficas, em especial nas zonas urbanas, não foi alterado pela circunstância. Apenas a possibilidade de audiências volantes, prevista pela lei, e que poderia realizar-se particularmente nas MJD, viria corrigir esta inadaptação ${ }^{14}$. É a proximidade no tempo que - mesmo não sendo mais designada desta maneira - está fundamentalmente no centro da reforma: trata-se, antes de tudo, de "arejar" os órgãos de primeiro grau, sobrecarregados, em particular pelos contenciosos civis de massa. Assim como indica o relatório feito em nome da comissão de leis da Assembleia Nacional, "a transferência de contenciosos a juízes não profissionais deve, em primeiro lugar ${ }^{15}$, permitir aliviar a carga de trabalho dos tribunais de instância que tiveram que fazer face nos últimos anos a um alargamento das suas competências. Deve igualmente permitir oferecer um tratamento judicial renovado aos litígios da vida cotidiana...".

Os primeiros juízes de proximidade entraram em função a partir de outubro de 2003. O projeto inicial não é sem ambição dado que prevê o recrutamento de 3.300 novos juízes ${ }^{16}$. São hoje menos de 500. Em Chiffres-clés de la justice [Números-chave da justiça] de 2004, os juízes de proximidade

\footnotetext{
${ }_{13}$ Comissão de leis da Assembleia Nacional.

${ }^{14}$ As recomendações do grupo de trabalho sobre as jurisdições de proximidade (cf. infra, p. 86) a respeito da realização de audiências volantes deixam supôr que esta possibilidade não foi ainda utilizada até o presente.

${ }^{15}$ Grifo da autora.

${ }^{16} \mathrm{Ou}$ seja, a metade do número de magistrados profissionais actualmente em exercício.
} 
não aparecem nos casos julgados no civil. No penal, recenseia-se no seu ativo 4.700 casos para 1.386 .000 de casos judicializados. A entrada em vigor da reforma de 2005, que perseguia explicitamente este objetivo, provocará um crescimento sensível da sua atividade em matéria civil.

Em 2005, um primeiro balanço das atividades das jurisdições de proximidade é pedido a um grupo de trabalho que entrega o seu relatório em novembro. Este constata, de um lado, dificuldades - remediáveis - de implantação (erros de recrutamento, falta de meios para a formação, isolamento de alguns dos novos juízes propiciando "atitudes inábeis e impróprias") -, por outro lado, constata uma redução da carga judiciária em certo número de jurisdições. Mas a interrogação mais forte posta na conclusão "reside na própria identidade da justiça de proximidade. No que ela é e pode estar mais próxima? Em que reside seu valor agregado? A sua originalidade?" A partir disso, as propostas são centradas sobre a ideia de "dar mais conteúdo à noção de proximidade"...

\section{Dois impulsos quebrados}

Uma justiça pouco atenta ao humano, lenta, cara, mal adaptada e pouco compreensível em suas respostas, frequentemente difícil de ser alcançada fisicamente pelos jurisdicionados, tais são as múltiplas barreiras às quais "a" justiça de proximidade supostamente leva remédio. O diagnóstico é sem complacência, emitido de maneira consensual por parlamentares, magistrados, investigadores (Haenel e Arthuis, 1991; Faget, 1992; Commaille, 2000; Peyrat, 2002, entre outros). Na ocasião, além porém da espinhosa questão dos subúrbios, é toda a instituição judiciária e o conjunto do seu funcionamento que são postos sob acusação. Das casas de justiça aos juízes de proximidade, a vontade de mudança é inegável. Até onde vai esta mudança? A pergunta pode ser abordada sob dois ângulos: uma justiça diferente? Juízes diferentes, cidadãos ao serviço da justiça?

\section{Outra justiça?}

\section{Das MJD às jurisdições de proximidade ou da territorialização à gestão dos contenciosos de massa}

A primeira justiça de proximidade representa uma exceção na paisagem francesa das reformas. O impulso vem de baixo, de indivíduos isolados, certamente institucionalizados, mas operando por sua própria iniciativa, sem entrar num quadro que teria sido traçado para eles em nível nacional. "A" justiça de proximidade não tem nessa época nada de homogêneo, as práticas 
variam conforme a imaginação dos procuradores. A proximidade remete a uma abordagem de territorialização, no sentido pleno do termo, a uma adaptação da resposta judicial aos lugares e às pessoas. A aposta consiste em "fazer diferente" e, mesmo se articulada à preocupação de descongestionar a instituição penal, a preocupação qualitativa precede a da quantidade.

A partir deste militantismo dos procuradores, verdadeiras transformações vão afetar a instituição judicial. "Ir para o exterior" (outros lugares, outros atores, outros procedimentos) permitiu transformações internas. O dinamismo de alguns procuradores logrou sucesso no seu esforço: suscitar mudança em uma instituição conhecida pelo seu imobilismo. A mediação penal gerou assim um leque de alternativas ao processo que enriqueceu o rol de respostas penais, em especial para os menores (Wyvekens, 1998). Advertência [rappel à la loi], suspensão condicional [classement sous condition], composição penal ocupam hoje um bom espaço no código de processo penal e nas estatísticas da justiça.

Mas o retorno ao colo dos palácios e dos códigos marca também o limite da aventura. Essa justiça não é mais uma justiça de proximidade. O seu conteúdo específico pouco a pouco tem sido marginalizado, em proveito da resposta a uma lógica de gestão dos contenciosos de massa. A preocupação de "fazer melhor" cedeu o lugar à preocupação de "fazer mais". E isso sob risco de abrir o flanco a uma dupla crítica: no plano "técnico", a tendência ao "culto aos números"17 que acompanha este tipo de lógica (Bastard e Mouhanna, 2006) e, num plano mais ideológico, a denúncia de uma generalização das respostas judiciais constitutiva de "penalização do social" (Bonelli e Sainati, 2001).

Se se deixou alguns magistrados inventivos trabalharem em algumas instâncias particularmente expostas, não se tem tomado realmente a sério a parte "feita à mão" do que estavam a inventar. Em todo caso, menos que o escasso gosto da maioria dos magistrados pelo deslocamento, aventureiro a seu ver, que representa a realização de audiências em bairros pouco seguros. Em 2002, o magistrado que foi encarregado da coordenação da política urbana no Ministério da Justiça, recordando que "o programa que foi atribuído à [justiça de proximidade] - prevenção da delinquência, tratamento rápido dos pequenos conflitos, atenção às vítimas, acesso ao direito - é uma missão de interesse geral, que não deveria comportar exceção no território nacional", lamentava o caráter "largamente lacunário" da rede das casas e antenas de justiça e expressava seus votos pela sua generalização (Peyrat, 2002, p. 6). Três anos depois, constatava: “... após treze anos de construção arfante, de

${ }^{17}$ No original, “barèmisation”, que em tradução literal seria o domínio das tabelas. (Nota do tradutor) 
coordenação ilegível e marginalização do seu pessoal (...), as MJD vegetam na periferia da instituição..." (Peyrat, 2005, p. 162).

Nunca, com efeito, se divisou generalizar o escopo desta ação: a possibilidade de inventar.

\section{Outros juízes?}

\section{Do "cidadão ao serviço da justiça" ao "juiz à parte na organização judicial" 18}

A primeira justiça de proximidade tinha deixado integralmente a questão da melhoria do tratamento dos contenciosos civis. $\mathrm{O}$ desenvolvimento - desejado (Vignoble, 1995) - da conciliação civil nas casas de justiça não ocorreu. Uma relativa aproximação, se não da justiça judicial, ao menos da informação jurídica, foi incentivada, além da vertente de acesso ao direito das casas de justiça, pelo impulso mais geral dado pela lei de 18 de dezembro de 1998 , nos termos da qual um conselho departamental de acesso ao direito (CDAD) deveria ser criado em cada departamento. Mas o tratamento dos "pequenos litígios" civis permanece insatisfatório: as jurisdições civis de primeira instância estão congestionadas, e os litigantes renunciam muito frequentemente a recorrer a eles em razão do custo, da lentidão, e da complexidade dos procedimentos. Se porém a denominação é idêntica, e os argumentos justificadores análogos, o que está em jogo na justiça de proximidade do início anos 2000 é outra coisa: assim como destaca o Relatório Charvet (2001, p. 9), evocando, para recordar os objetivos da reforma, diversos relatórios anteriores, "o tratamento do contencioso de massa em matéria civil está no coração de todas as reflexões".

Não está mais em questão aqui o território nem adaptar a justiça. Se se pretende modificar os modos de intervenção, é atualmente - nas intenções ao menos - introduzindo na instituição um ator novo, melhor, um juiz novo: um juiz não profissional, "um cidadão ao serviço da justiça", mais próximo dos litigantes e que julgará diferentemente, de maneira mais "humana": "Os juízes de proximidade devem ser recrutados o mais largamente possível na sociedade civil... Não há nenhuma dúvida que as qualidades humanas e psicológicas assim como a disponibilidade parecem tão importantes quanto as competências jurídicas... Os cidadãos estão, com efeito, no direito de esperar um juiz que dê provas sobretudo de bom senso e que disponha de um bom conhecimento das coisas da vida e, por conseguinte, uma grande

\footnotetext{
${ }^{18}$ É assim que são qualificados no sítio vie publique.fr: http://www.vie-publique.fr/politiquespubliques/juge-justiceproximite/juges-proximité/organisation-judiciaire
} 
capacidade de escuta. [...] Parece então importante que as características dos juízes de proximidade, tendo a vocação de pacificar os conflitos e julgar em equidade, diferem daquelas dos magistrados profissionais, que se apresentam essencialmente como técnicos do direito encarregados de fazer prevalecer a regra de direito"19. A ideia de uma justiça qualitativamente diferente, longe de estar ausente, como se vê, é posta ao centro da reforma. Mas, entre as declarações de intenção e o desenrolar da história do novo órgão jurisdicional, a defasagem é grande.

Isto vai pesar precisamente sobre a pessoa do juiz, e essa será a segunda aposta frustrada da justiça de proximidade.

Pôr os cidadãos ao serviço da justiça, certamente... Mas, ao final, não qualquer cidadão! Desde o voto da lei orgânica, o novo impulso encontra-se comprometido: um recurso junto ao Conselho Constitucional desembocou numa decisão ${ }^{20}$ que restringe fundamentalmente o recrutamento dos novos juízes: os candidatos deverão obrigatoriamente comprovar uma experiência ou conhecimentos no domínio jurídico. Paralelamente - e não sem relação - a recepção pelos magistrados profissionais à jurisdição de proximidade não é nada menos que enérgica. O Relatório Charvet evoca sua "franca hostilidade", tanto na origem quanto no momento da extensão de competências introduzida pela lei de 2005 .

O perfil do juiz põe a sua marca sobre a natureza de sua atividade. Desde a origem, e cada vez mais ao longo do tempo, observa-se " $a$ inclinação da nova instituição para o mimetismo em relação à justiça de instância" (Relatório Charvet, 2001, p. 53). Juízes juristas, julgando pelo direito e não pela equidade, constrangidos pelos juízes profissionais a se conformarem à redação de julgamentos, os quais a lei autoriza substituir naturalmente os juízes de instância, vão encontrar-se na sequência, pela lei de 2005, mais "desespecializados" ainda: anteriormente competentes unicamente para os "pequenos" litígios entre particulares podem doravante ser acionados também pelas pessoas jurídicas, e para litígios claramente mais importantes.

Efetivamente criou-se um novo órgão jurisdicional, mas, ao não extremar a lógica que consiste em "associar cidadãos à justiça", recusou-se a possibilidade de alterar os modos de tratamento. $\mathrm{O}$ discurso que cerca a reforma baseava-se na imagem de um ser humano próximo dos usuários da justiça, "outro" juiz. Ao cabo, uma estrutura jurisdicional suplementar e bem pouco diferente foi criada. As conclusões e propostas do Relatório Charvet

\footnotetext{
19 Relatório da comissão de leis da Assembleia Nacional (Relatório Fauchon).

20 Decisão n ${ }^{\circ}$ 2003-466 CD do Conselho Constitucional de 20 de fevereiro de 2003.
} 
são a esse respeito eloquentes: instaurar um recurso obrigatório à conciliação, pôr em experimento o julgamento em equidade, a justiça de proximidade está para ser "refeita". Mas "os cidadãos a serviço da justiça” existiram apenas no plano da retórica.

\section{Conclusão}

Duplo impulso, dupla incompletude. As conclusões sem complacência do relatório do grupo de trabalho podem deixar um gosto amargo e, ao mesmo tempo, sua natureza relança a reflexão, espera-se, no campo, a partir das propostas formuladas, e apoiando-se em breve sobre as novas investigações, lançados em 2006 por iniciativa da missão de investigação "Direito e justiça".

\section{Referências}

APAP, G. La conciliation pénale à Valence. Revue de science criminelle et de droit pénal comparé, Paris. juillet/septembre, 1990.

BASTARD, B.; MOUHANNA, C. L'urgence comme politique pénale? Le traitement en temps réel des affaires pénales. Archives de politique criminelle, Paris: Editions Pédone, n. 28, p. 153-166, 2006.

BONELli, L.; SAINATI, G. (Dir.). La machine à punir. Pratiques et discours sécuritaires. Paris: L'Esprit frappeur, 2001.

CHARVET, Dominique. Jeunesse, le devoir d'avenir. Rapport de la commission "Jeunes et politiques publiques". La Documentation Française, Paris, 2001.

COMMAILLE, J. Territoires de justice. Une sociologie politique de la carte judiciaire. Paris: PUF, 2000.

COMMISSION des maires sur la sécurité. Face à la délinquance: prévention, répression, solidarité. Rapport au Primier Ministre. La Documentation Française ("Rapport Bonnemaison"), Paris, 1982.

FAGET, J. Justice et travail social. Le rhizome penal. Toulouse: Erès, 1992.

FAUCHON, P.; JOLIBOIS, Ch. Quels moyens pour quelle justice? Mission d' information de la commission des Lois chargée d'évaluer les moyens de la justice Rapport 49 - Paris, 1996/1997.

HAENEL, H.; ARTHUIS, J. Propositions pour une justice de proximité, 1994. . Justice sinistrée, démocratie en danger. Paris: Economica, 1991.

PEYRAT, D. En manque de civilité. Paris: Textuel, 2005.

. La justice de proximité, Problèmes politiques et sociaux. La Documentation française, Paris, n. 869, 2002.

RAPPORT du groupe de travail sur les juridictions de proximité, septembre 2003novembre 2005. Bilan et propositions, Paris, novembre 2005. 
VIGNOBLE, G. Les maisons de justice et du droit, rapport présenté au Garde des Sceaux, 1995.

WYVEKENS, A. Délinquance des mineurs: justice de proximité vs justice tutélaire. Esprit, mars-avril, p. 158-173, 1998.

WYVEKENS, A. Justice de proximité et proximité de la justice. Les maisons de justice et du droit. Droit et Société, Paris, n. 33, p. 363-388, 1996. 